\title{
Pancreatic Neuroendocrine Tumor pNO TNM Finding v8
}

National Cancer Institute

\section{Source}

National Cancer Institute. Pancreatic Neuroendocrine Tumor pNo TNM Finding v8. NCI Thesaurus. Code C135558.

Pancreatic neuroendocrine tumor without regional lymph node involvement. (from AJCC 8th Ed.) 